\title{
Retinal arteritis complicating herpes zoster ophthalmicus
}

\author{
R. M. BROWN AND UPALI MENDIS \\ Moorfields Eye Hospital, City Road, London, E.C.I
}

According to Duke-Elder ( 1965 ), ocular complications occur in about 50 per cent. of cases of herpes zoster ophthalmicus (HZO). However, the involvement of retinal vessels in the course of HZO is exceedingly rare (Walsh and Hoyt, I969) and there are few case reports in the entire ophthalmic literature. Retinal vascular changes previously described have been occlusion of the central retinal vein (Zolog and Popescu, 1957) and occlusion of the central retinal artery (Julien, 1952). In addition, Collier (1959) described a localized form of arteritis without retinal exudates and Koch (1949) reported a case of $\mathrm{HZO}$ in a child of 5 years who had mild arteriolar narrowing with small exudates in the macular region.

The case described below would appear to be unique, in that the branches of the retinal artery are involved with exudates in relation to the areas of supply.

\section{Case report}

A 60-year-old woman was seen in the out-patient department of Moorfields Eye Hospital in November, $197 \mathrm{I}$, with a history of blurred vision in the left eye for 2 months. The onset of symptoms occurred after an attack of HZO on the left side of the face, and the blurred vision had continued since then. She had no pain or redness in the eye. Seven years ago, she had had a radical mastectomy for carcinoma of the breast and had been found to have secondaries in the liver 5 years ago. She has remained in fair health ever since on treatment with prednisolone and antimetabolites (Endoxana).

\section{Examination}

The corrected visual acuity was 6/12 in the right eye and 6/24 in the left. Except for a few posterior subcapsular lens opacities, the right eye appeared normal. The left forehead showed scarring of the skin typical of HZO. The left eye had many pigmented keratic precipitates on the posterior surface of the cornea with flare and cells in the aqueous. The pupil was distorted and there was a localized area of iris atrophy with loss of pigment at 2 o'clock. The vitreous was hazy and the fundus showed sheathing and marked narrowing of the branches of the upper nasal and upper temporal arterioles. In the region of supply corresponding to these attenuated vessels, the retina showed extensive yellowish exudates (Fig. I). The other retinal vessels appeared normal and there were no haemorrhages. The ocular tensions were $18 \mathrm{~mm} . \mathrm{Hg}$ in the right eye and $40 \mathrm{~mm} . \mathrm{Hg}$ in the left. The left visual field showed large defects in the lower half which were consistent with the fundus findings. A diagnosis of uveitis with retinal arteritis complicating $\mathrm{HZO}$ was made in the absence of any other detectable cause.

\section{Therapy}

She was treated with predsol, atropine, and Diamox. 


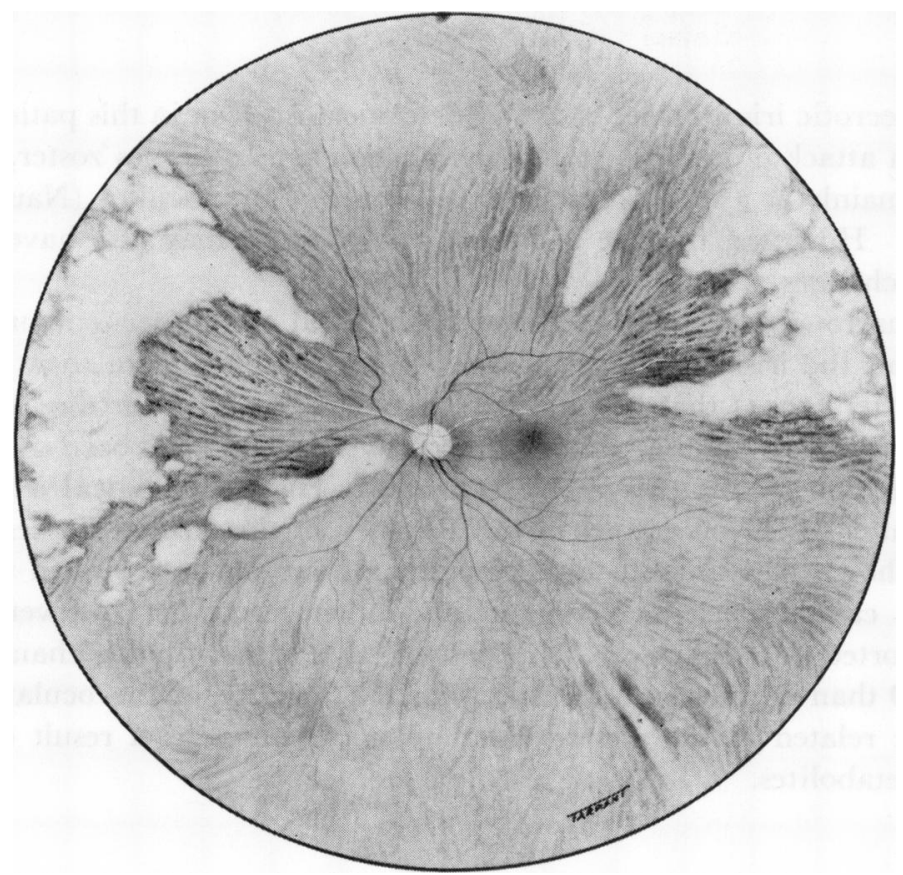

FI G. I Fundus painting, showing extensive exudatesinareas of supply of narrowed and sheathed upper nasal and upper temporal retinal arterioles

Result

Within a few days, the aqueous and vitreous cleared and the ocular tension in the left eye became normal.

Fluorescein angiography of the fundus showed filling of all the retinal arterial branches, but there was narrowing and extremely slow transit of the dye in the upper nasal and upper temporal branches. There was progressive leakage of fluorescein into the retina in the region of exudation (Fig. 2).

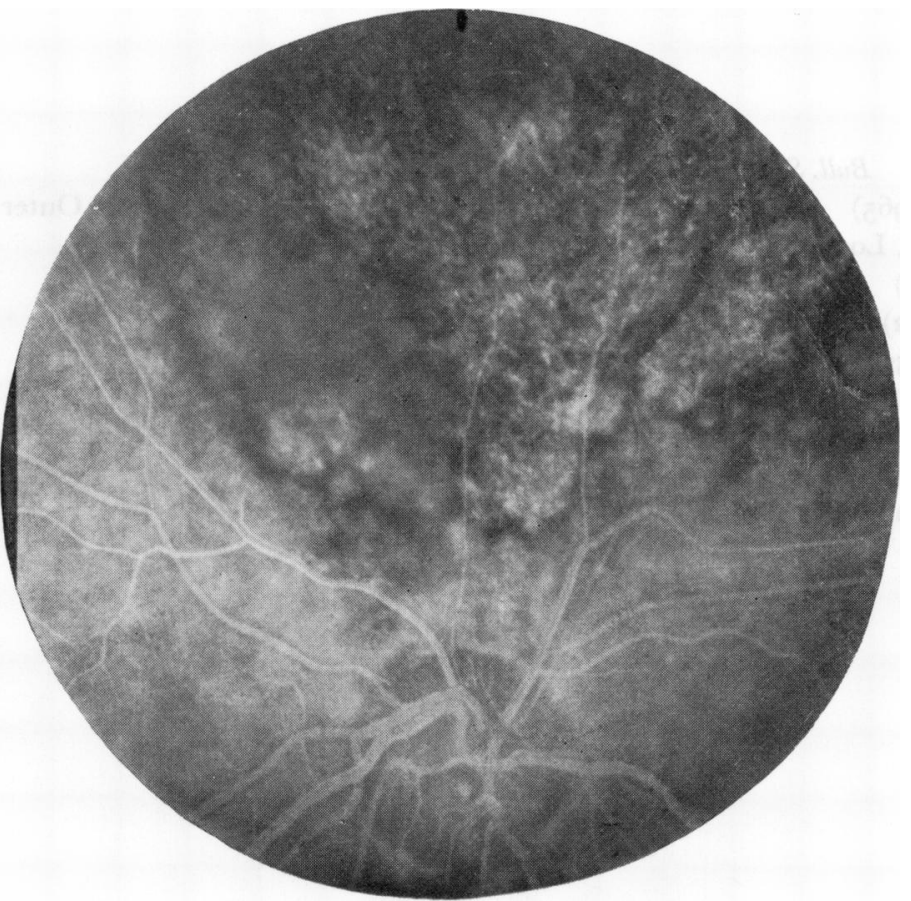

FIG. 2 Fluorescein angiography of fundus, demonstrating leakage of dye in area of exudation 


\section{Discussion}

The patchy postnecrotic iris atrophy after sphincter necrosis seen in this patient resembles that seen after an attack of acute-closed angle glaucoma. In herpes zoster, the necrosis probably occurs mainly as a result of ischaemia secondary to vasculitis (Naumann, Gass, and Font, 1968). However, the rise in intraocular pressure may also have contributed to these atrophic changes.

The extensive narrowing of the branches of upper nasal and upper temporal arterioles, with exudates, and the iris changes seen in this patient would seem to fit the original hypothesis of Feyrter (I954) that herpes zoster is basically a vascular disease resembling and related to polyarteritis nodosa, although most investigators have been more impressed by the perineural than by the perivascular changes. Histopathological examination of eyes enucleated after HZO on record in the Registry of the Armed Forces Institute of Pathology have shown perivasculitis and vasculitis of varying intensity in the retina in twelve of the 2 I cases reported (Naumann and others, 1968). However, no fundus changes were reported in these cases. It is possible that minor fundus changes are more common in $\mathrm{HZO}$ than is believed. In addition, the severity of the ocular reaction in this case may be related to the altered immunological status as a result of the treatment with antimetabolites.

\section{Summary}

A case of retinal arteritis complicating $\mathrm{HZO}$ is described as a rare manifestation of this condition.

The authors wish to express their thanks to Mr. J. E. M. Ayoubfor permission to publish this case, Mr. T. Tarrant for the fundus painting, and the Retinal Diagnostic Unit of Moorfields Eye Hospital for the fluorescein studies.

\section{References}

COllier, M. (1959) Bull. Soc. Ophtal.Fr., p.737

DUKe-ELDER, s. (1965) "System of Ophthalmology", vol. 8. "Diseases of the Outer Eye", pt i, p. 340. Kimpton, London

FEYRTER, F. (1954) Virchows Arch. path. Anat., 325, 70

JULIEN, R. G. (1952) Bull. Soc. Ophtal. Fr., p. 842

косн, F. L. P. (1939) Arch. Ophthal. (Chicago), 21, 118

naumanN, G., Gass, J. D. M., and Font, R. L. (I968) Amer. F. Ophthal., 65, 533

WALSH, F. B., and HOYT, W. F., (1969) "Clinical Neuro-ophthalmology", 3rd. ed., vol. 2, p. 135I.

Williams and Wilkins, Baltimore

zOLOG, N., and POPESCU, E. (1957) Oftalmologia (Bucuresti), 2, $34^{\circ}$ 